Supporting Information for

\title{
Ternary Palladium-Boron-Phosphorus Alloy Mesoporous Nanospheres for Highly Efficient Electrocatalysis
}

Hao Lv, ${ }^{1}$ Dongdong Xu, ${ }^{1}$ Lizhi Sun, ${ }^{1}$ Joel Henzie, ${ }^{2,3}$ Steven L. Suib,${ }^{4}$ Yusuke Yamauchi, $, 25,6$ and Ben $\operatorname{Liu}^{1, *}$

${ }^{1}$ Jiangsu Key Laboratory of New Power Batteries, Jiangsu Collaborative Innovation Center of Biomedical Functional Materials, School of Chemistry and Materials Science, Nanjing Normal University, Nanjing 210023, China

*Email: ben.liu@njnu.edu.cn

${ }^{2}$ Key Laboratory of Eco-chemical Engineering, College of Chemistry and Molecular Engineering, Qingdao University of Science and Technology, Qingdao 266042, China

${ }^{3}$ International Center for Materials Nanoarchitectonics (WPI-MANA), National Institute for Materials Science (NIMS), 1-1 Namiki, Tsukuba, Ibaraki 305-0044, Japan

${ }^{4}$ Department of Chemistry and Institute of Materials Science, University of Connecticut, Storrs, Connecticut, 06269, United States

${ }^{5}$ School of Chemical Engineering and Australian Institute for Bioengineering and Nanotechnology (AIBN), The University of Queensland, Brisbane, QLD 4072, Australia

${ }^{6}$ Department of Plant \& Environmental New Resources, Kyung Hee University, 1732 Deogyeong-daero, Giheung-gu, Yongin-si, Gyeonggi-do 446-701, South Korea 


\section{Figure Contents}

Supporting Figure S1. Supporting TEM images of dendritic PdBP MSs with different magnifications.

Supporting Figure S2. Supporting HAADF-STEM images of dendritic PdBP MSs with different magnifications.

Supporting Figure S3. SAXS pattern of the ternary PdBP MSs.

Supporting Figure S4. High-resolution XPS Pd 3d spectra of monometallic Pd MSs.

Supporting Figure S5. The effect of amphiphilic surfactants in the surfactant-templating formation of ternary PdBP nanoalloys.

Supporting Figure S6. The effect of $\mathrm{NH}_{3} \cdot \mathrm{H}_{2} \mathrm{O}(\mathrm{pH})$ in controlling the dendritic diameters of ternary PdBP alloy MSs.

Supporting Figure S7. The effect of the DODAC concentrations in controlling the dendritic diameters of ternary PdBP alloy MSs.

Supporting Figure S8. The effect of the Pd precursor concentrations in controlling the dendritic diameters of ternary PdBP alloy MSs.

Supporting Figure S9. Structural and compositional characterizations of ternary PdBP alloy MSs with different P contents.

Supporting Figure S10. Structural characterizations of ternary PdBP alloy MSs and PdBP alloy NPs loaded on Vulcan XC-72 carbon, in addition to commercial Pt NPs on carbon.

Supporting Figure S11. The calculated ECSAs of the PdBP MSs, PdB MSs, Pd MSs, PdBP NPs, commercial Pt and Pd NPs.

Supporting Figure S12. ORR polarization curves of the PdBP NPs, commercial Pt and Pd NPs before and after 5,000 cycles of potential sweeps.

Supporting Figure S13. Structural characterization of PdBP NPs, commercial Pt NPs, and PdNPs after 5,000 potential sweeps using electrochemical ORR conditions.

Supporting Figure S14. Electrocatalytic CO stripping curves of ternary PdBP alloy MSs, binary PdB alloy MSs, and monometallic Pd MSs.

Supporting Figure S15. CV curves of ternary PdBP alloy MSs and commercial Pd NPs in $0.5 \mathrm{M} \mathrm{H}_{2} \mathrm{SO}_{4}$ and 1.0 $\mathrm{M}$ formic acid, 1.0 KOH and 1.0 M methanol, and 1.0 M KOH and 1.0 M glycerol.

Supporting Table S1. Summarization of electrochemical ORR performance of the Pd-based nanoalloys in an alkaline media. 


\section{Chemicals and Materials}

Palladium(II) chloride $\left(\mathrm{PdCl}_{2}, 99.9\right.$ wt. \%), ammonium fluoride $\left(\mathrm{NH}_{4} \mathrm{~F}\right)$, boric acid $\left(\mathrm{H}_{3} \mathrm{BO}_{3}\right)$, borane dimethylamine complex (DMAB), sodium hypophosphite $\left(\mathrm{NaH}_{2} \mathrm{PO}_{2}\right)$, dioctadecyldimethylammonium chloride (DODAC), didodecyldimethylammonium chloride (DDDAC), dioctyldimethylammonium chloride (DODAC-2), cetyltrimethylammonium chloride ( $\left.\mathrm{C}_{16} \mathrm{TAC}\right)$, octadecyltrimethylammonium chloride (C $\left.18 \mathrm{TAC}\right)$, Pluronic F127 orthoboric, ascorbic acid (AA), and acetic acid were obtained from Alfa Aesar. Nafion solution, commercial palladium nanoparticles (Pd NPs) and Pt NPs were obtained from Sigma-Aldrich. Hydrochloric acid $(\mathrm{HCl})$, ammonia solution $\left(\mathrm{NH}_{3} \cdot \mathrm{H}_{2} \mathrm{O}\right)$ and sodium hydroxide $(\mathrm{NaOH})$ were purchased from Sinopharm Chemical Reagent Co. Ltd. (Shanghai). Behenyl trimethyl ammonium chloride $\left(\mathrm{C}_{22} \mathrm{TAC}\right)$ was synthesized according to our previously reported work (Chem. Sci. 2018, 9, 4451; J. Phys. Chem. Lett. 2019, 10, 663). To prepare $10 \mathrm{mM} \mathrm{H}_{2} \mathrm{PdCl}_{4}$ solution, $0.355 \mathrm{~g}$ of $\mathrm{PdCl}_{2}$ was first dissolved into $20 \mathrm{~mL}$ of $0.2 \mathrm{M} \mathrm{HCl}$ solution, and then diluted with deionized $\mathrm{H}_{2} \mathrm{O}$ to 200 $\mathrm{mL}$. Deionized $\mathrm{H}_{2} \mathrm{O}$ with the resistivity of $18.25 \mathrm{~m} \Omega$ was used in all experiments.

\section{Synthesis of ternary PdBP alloy mesoporous spheres (MSs)}

Ternary PdBP alloy MSs were synthesized by an aqueous route using $\mathrm{H}_{2} \mathrm{PdCl}_{4}$ as the metal precursor, DODAC as the surfactant template, $\mathrm{NaH}_{2} \mathrm{PO}_{2}$ as the $\mathrm{P}$ source and $\mathrm{DMAB}$ as the $\mathrm{B}$ source at $95{ }^{\circ} \mathrm{C} . \mathrm{NaH}_{2} \mathrm{PO}_{2}$ and $\mathrm{DMAB}$ were also used as the co-reducing agents to drive the crystalline nucleation and growth of the PdBP alloys. In a typical synthesis, $15 \mathrm{mg}$ of DODAC was totally dissolved in $5 \mathrm{~mL}$ of deionized $\mathrm{H}_{2} \mathrm{O}$ to obtain a homogeneous solution, followed by the addition of $0.5 \mathrm{~mL}$ of $0.337 \mathrm{M} \mathrm{NH}_{4} \mathrm{~F}$ solution, $0.5 \mathrm{~mL}$ of $0.101 \mathrm{M} \mathrm{H}_{3} \mathrm{BO}_{3}$ solution, and $0.4 \mathrm{~mL}$ of $10 \mathrm{mM} \mathrm{H}{ }_{2} \mathrm{PdCl}_{4}$ solution. After incubated for $5 \mathrm{~min}, 0.2 \mathrm{~mL}$ of $\mathrm{NH}_{3} \cdot \mathrm{H}_{2} \mathrm{O}(10 \mathrm{wt}$. \%) was injected to adjust the $\mathrm{pH}$ of the solution. The color of the solution was changed from pink to colorless correspondingly. Then, $0.5 \mathrm{~mL}$ of $0.034 \mathrm{M} \mathrm{NaH}_{2} \mathrm{PO}_{2}$ was mixed into the above solution, and further incubated at $95{ }^{\circ} \mathrm{C}$ for $20 \mathrm{~min}$. Lastly, $0.5 \mathrm{~mL}$ of freshly prepared 0.1 M DMAB was injected to start the reduction. In this stage, the color of the solution gradually evolved and became dark brown. After kept at $95{ }^{\circ} \mathrm{C}$ for $30 \mathrm{~min}$, the product was collected by centrifuged and washed several times with ethanol/ $\mathrm{H}_{2} \mathrm{O}$. Besides, $\mathrm{pH}$, reaction temperatures, $\mathrm{H}_{2} \mathrm{PdCl}_{4}$ and DODAC amounts, $\mathrm{NaH}_{2} \mathrm{PO}_{2}$ amount, and the species of the surfactants were also tuned to tailor the nanostructures of as-resulted PdBP MSs under the similar procedures.

Binary PdB alloy MSs were synthesized using the similar procedures, but only using DMAB as the B source and reducing agent solely at $75{ }^{\circ} \mathrm{C}$ (without $\mathrm{NaH}_{2} \mathrm{PO}_{2}$ ), while Monometallic Pd MSs were obtained using ascorbic acid as the reducing agent (see Chem. Sci. 2019, 10, 1986 for more synthetic details). 


\section{Electrochemical measurements}

Electrochemical ORR measurements were carried out using a three-electrode system at $25^{\circ} \mathrm{C}$, with a rotating ring disk electrode (RDE, $0.237 \mathrm{~cm}^{2}$ ) connected to an CHI750E electrochemical workstation, a carbon rod as the counter electrode, and a saturated calomel electrode as the reference electrode. All the potentials were converted into the values with referencing to a reversible hydrogen electrode (RHE). Before the electrochemical tests, assynthesized nanocatalysts were cleaned with ethanol $/ \mathrm{H}_{2} \mathrm{O}$ and acetic acid for several times to completely remove the surfactants (Chem. Sci. 2019, 10, 1986; ACS Cent. Sci. 2018, 4, 1412). Then, obtained nanocatalysts were freezedried at $-60{ }^{\circ} \mathrm{C}$. To prepare an ink of the naocatalysts, $1 \mathrm{mg}$ of the nanocatalysts and $4 \mathrm{mg}$ of Vulcan XC-72 carbon were added to $0.8 \mathrm{~mL}$ of ethanol and $0.2 \mathrm{~mL}$ of $\mathrm{H}_{2} \mathrm{O}$, and further mixed by sonicating for $0.5 \mathrm{~h}$. Subsequently, 50 $\mu \mathrm{L}$ of Nafion solution ( 5 wt. \% in alcohol and $\mathrm{H}_{2} \mathrm{O}$ ) was added and sonicated for another $0.5 \mathrm{~h}$. Then, $10 \mu \mathrm{L}$ of above-prepared ink solution ( $10 \mu \mathrm{g}$ of the nanocatalyst) was dropped on the RDE electrode and dried at $40{ }^{\circ} \mathrm{C}$ before the test. Cyclic voltammograms (CVs) were then scanned until the stabilized curves were obtained for further removal of the surfactant in $\mathrm{N}_{2}$-saturated $0.1 \mathrm{M} \mathrm{KOH}$. CVs were used to evaluate the electrochemical surface areas (ECSAs) of the nanocatalysts with the scan rate of $50 \mathrm{mV} \mathrm{s}^{-1}$. ORR polarization curves of the nanocatalysts were measured in the potential range of $0.2-1.05 \mathrm{~V}$ in $\mathrm{O}_{2}$-saturated $0.1 \mathrm{M} \mathrm{KOH}$ with a rotating speed of $1600 \mathrm{rpm}$ at a scanning rate of $10 \mathrm{mV} \mathrm{s}^{-1}$. Ir compensation and background current correction were applied to the ORR measurements for all the nanocatalysts. Accelerated durability tests were performed by 5,000 cycles of potential sweeps $(0.5-1.1 \mathrm{~V})$ in $\mathrm{O}_{2}$-saturated $0.1 \mathrm{M} \mathrm{KOH}$. The $\mathrm{CVs}$ and $\mathrm{ORR}$ polarization curves were also measured after the accelerated durability tests. And, the samples after the stability tests were also collected from the RDE electrode for evaluating the structural stability by TEM.

CO stripping tests were carried out according to our previous work (ACS Cent. Sci. 2018, 4, 1412). Typically, the working electrode containing $3.0 \mu \mathrm{g}$ of the catalyst was immersed in $1 \mathrm{M} \mathrm{KOH}$ solution. Then, $\mathrm{CO}$ was purged in the solution for $30 \mathrm{~min}$ to achieve the maximum coverage of $\mathrm{CO}$ at a fixed potential of $0.15 \mathrm{~V}$ (SCE). After that, the electrode was moved into fresh $\mathrm{N}_{2}$-purged $1.0 \mathrm{M} \mathrm{KOH}$ solution for $\mathrm{CO}$ stripping measurements. $\mathrm{CO}$ stripping voltammetry was recorded in the potential range between -0.9 and $0.2 \mathrm{~V}$ at a scan rate of $50 \mathrm{mV} \mathrm{s}^{-1}$.

\section{Characterizations}

Transmission electron microscopy (TEM) and high-resolution TEM studies were carried out using a JEOL 2010 TEM with an accelerating voltage of $200 \mathrm{kV}$. High-angle annular dark-field scanning TEM (HAADF-STEM) and corresponding line scan analysis were performed on FEI Talos F200X apparatuses at an accelerating voltage of 200 $\mathrm{kV}$, which are equipped with STEM and EDS detectors for elemental mapping analysis. TEM and STEM samples were prepared by casting a suspension of the samples (in ethanol and/or $\mathrm{H}_{2} \mathrm{O}$ ) on a carbon coated copper grid (300 mesh). X-ray diffraction (XRD) patterns were collected on the powder samples using a D/max $2500 \mathrm{VL} / \mathrm{PC}$ diffractometer (Japan) equipped with graphite-monochromatized $\mathrm{Cu} \mathrm{K} \alpha$ radiation. X-ray photoelectron spectra 
(XPS) were performed on a scanning X-ray microprobe (Thermo ESCALAB 250Xi) that uses Al K $\alpha$ radiation. The binding energy of the $\mathrm{C} 1 \mathrm{~s}$ peak $(284.8 \mathrm{eV})$ was employed as a standard to calibrate the binding energies of other elements. Inductively coupled plasma mass spectrometry (ICP-MS) was recorded on a NexION 350D. Small-angle X-ray scattering (SAXS) analysis was carried out on a D5005 powder diffractometer (Bragg-Brentano fixed sample theta-theta geometry) with a scintillation point detector. 


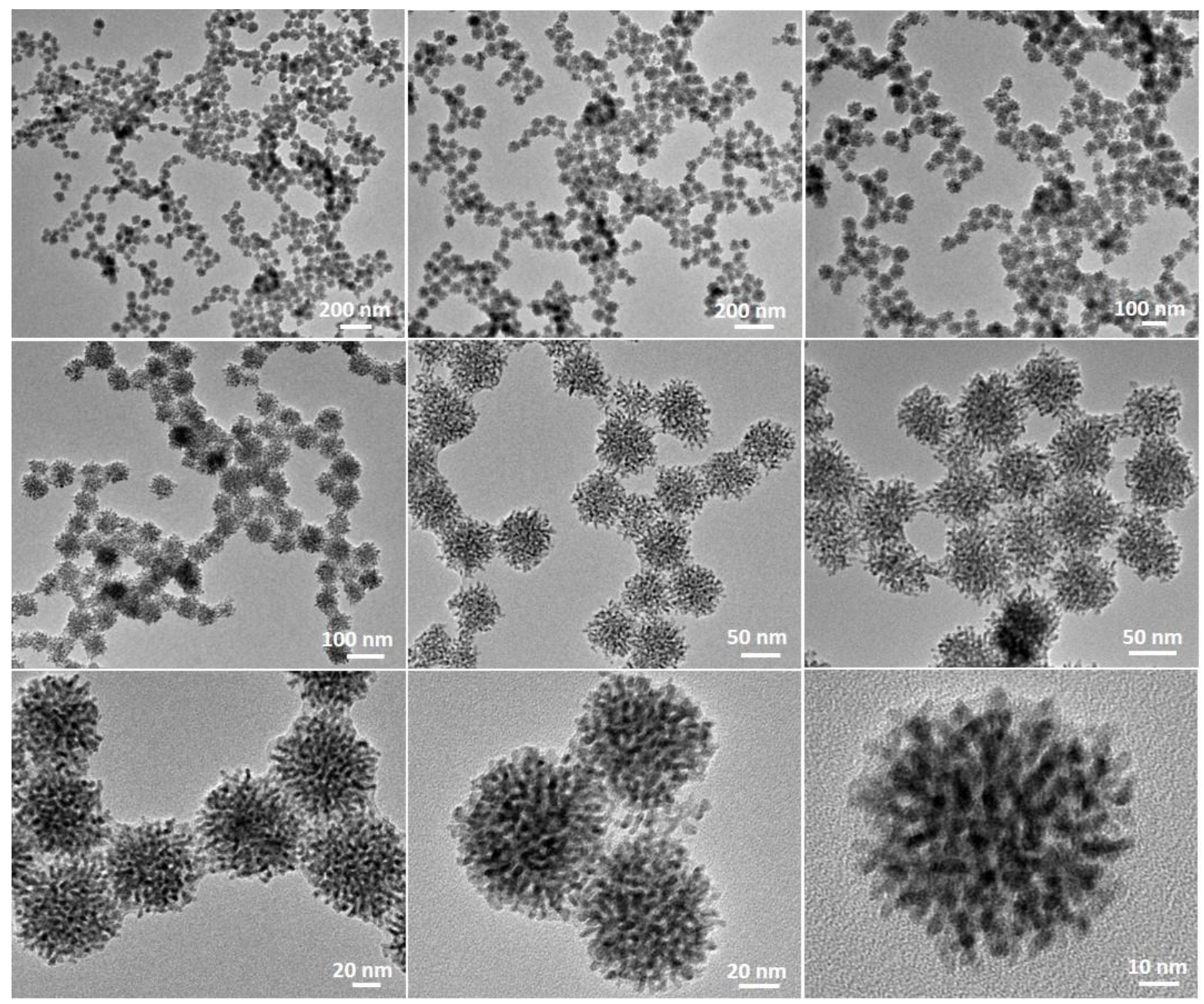

Figure S1. Supporting TEM images of dendritic PdBP MSs with different magnifications, highlighting high uniformity, monodispersity and purity. 


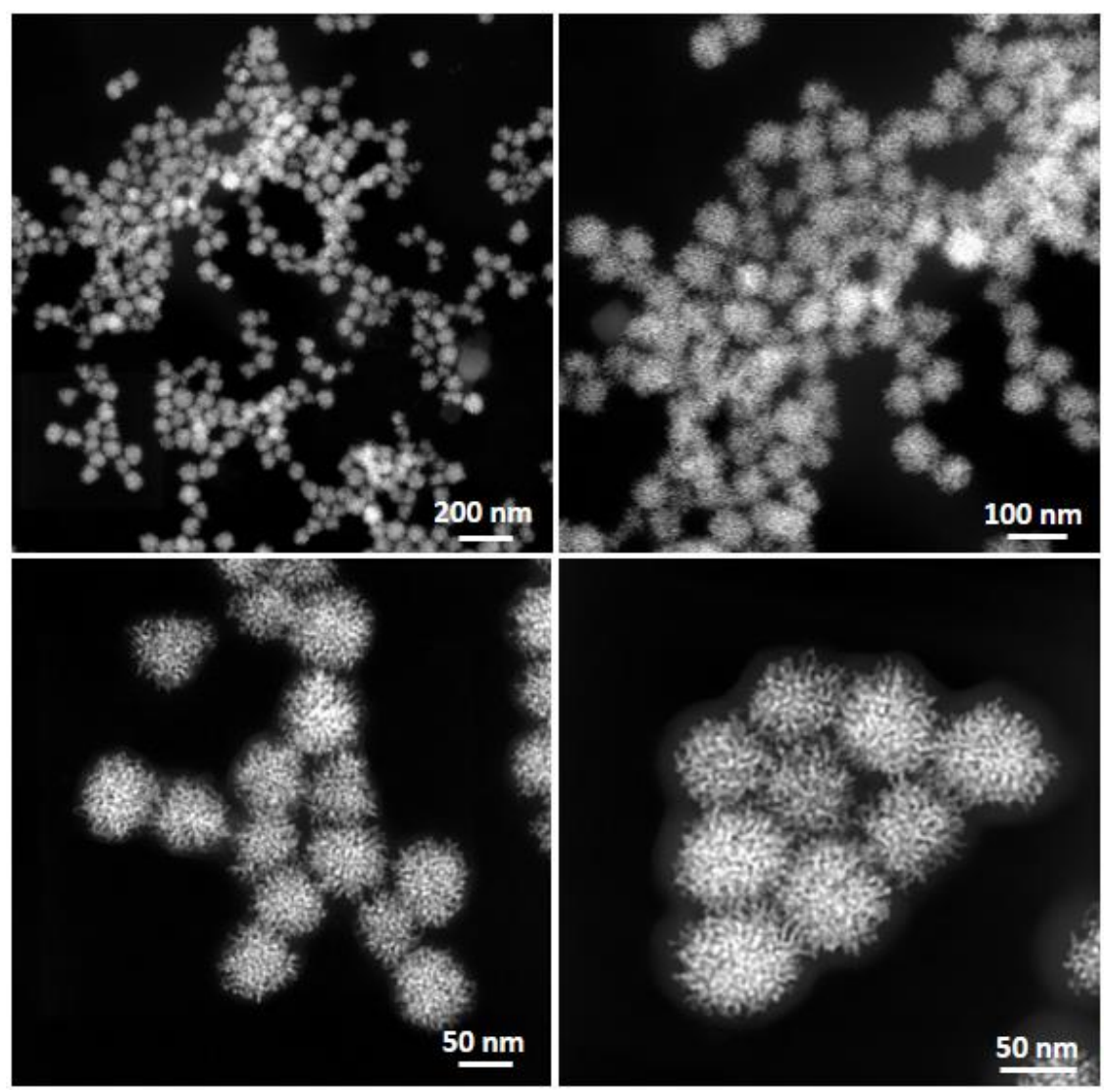

Figure S2. HAADF-STEM images of ternary PdBP alloy MSs with different magnifications.

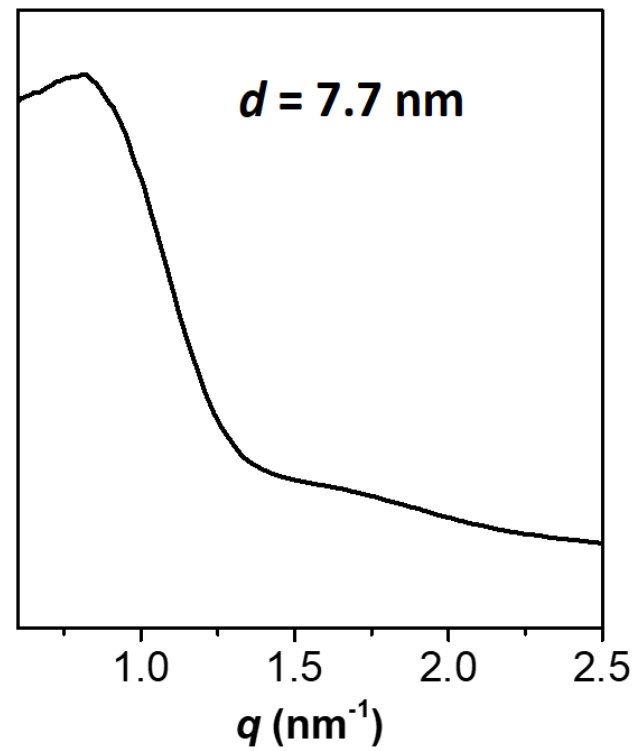

Figure S3. SAXS pattern of the ternary PdBP MSs. 


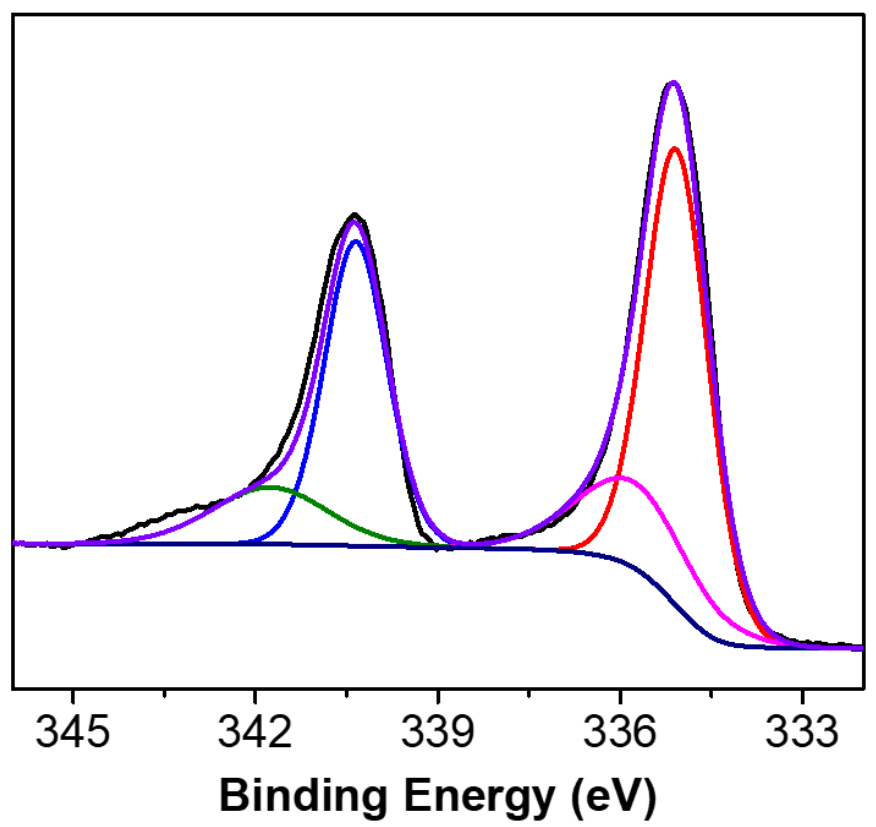

Figure S4. High-resolution XPS Pd 3d spectra of monometallic Pd MSs. 

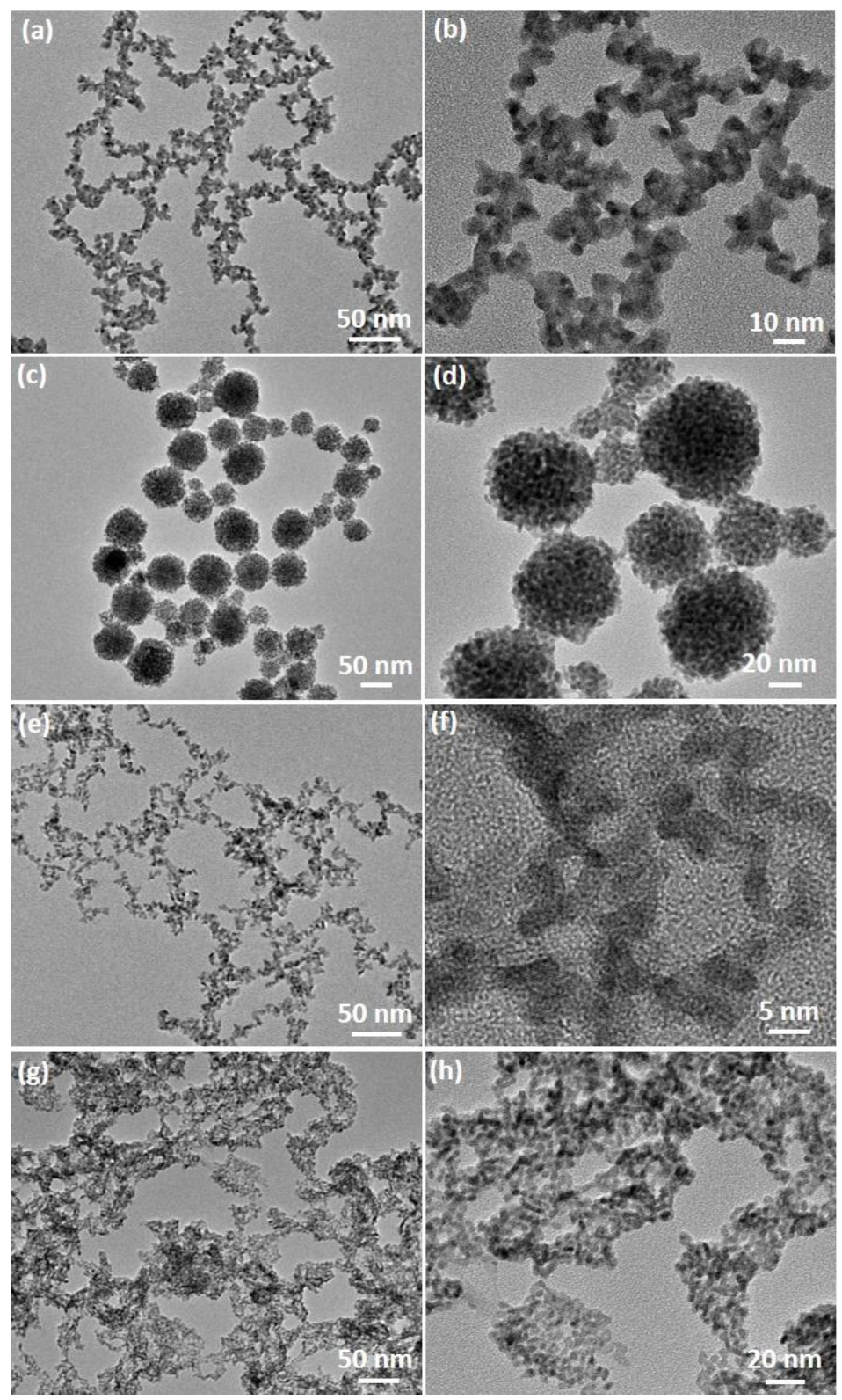

Figure S5. The effect of amphiphilic surfactants in the surfactant-templating formation of ternary PdBP nanoalloys. Typical TEM images of the PdBP nanostructures synthesized with the surfactant of (a, b) DODAC-2, (c, d) DDDAC, (e, f) $\mathrm{C}_{18} \mathrm{TAC}$, and $(\mathrm{g}, \mathrm{h}) \mathrm{C}_{22} \mathrm{TAC}$. 

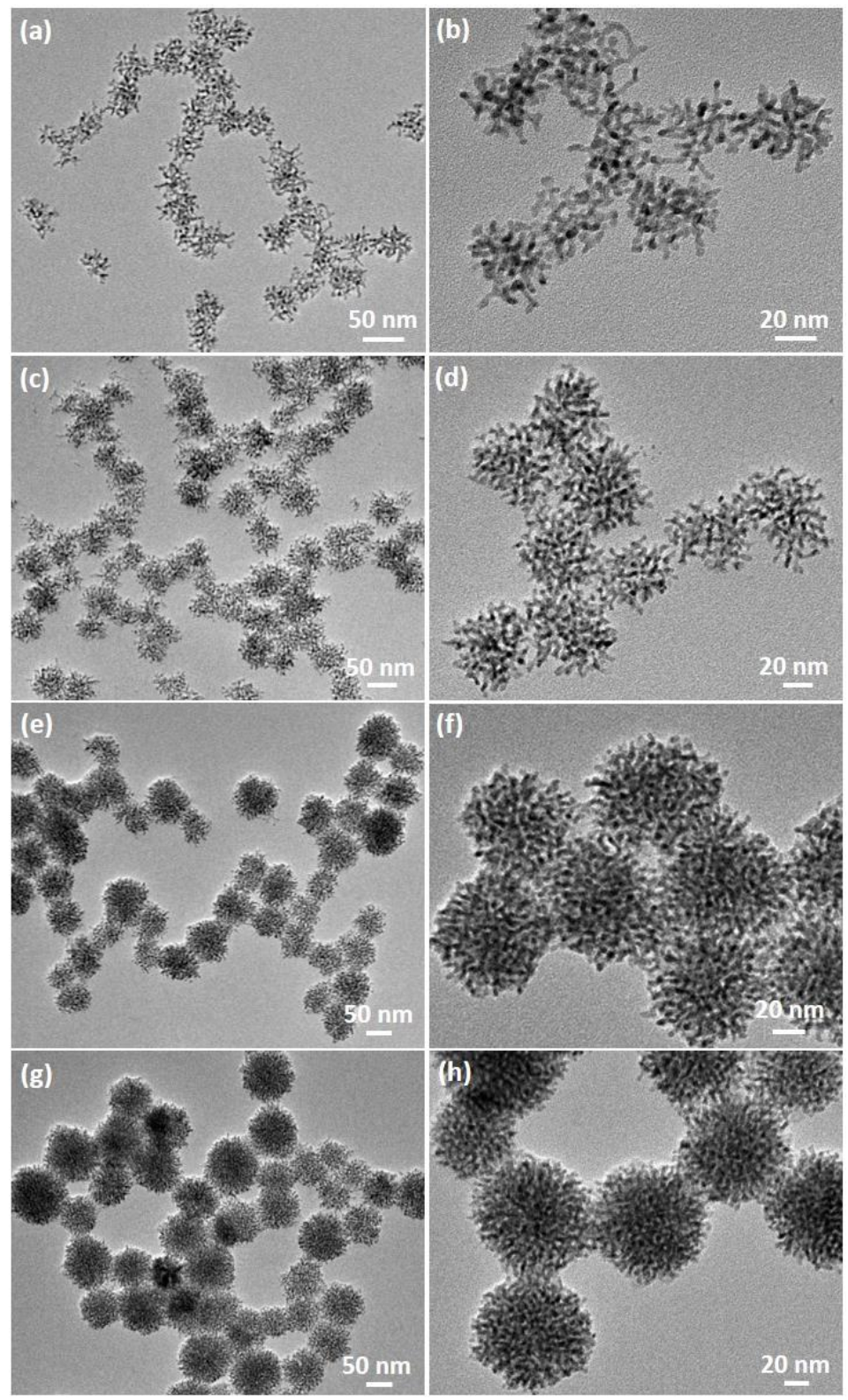

Figure S6. The effect of $\mathrm{NH}_{3} \cdot \mathrm{H}_{2} \mathrm{O}(\mathrm{pH})$ in controlling the dendritic diameters of ternary PdBP alloy MSs. Typical TEM images of the PdBP MSs synthesized with initial $\mathrm{NH}_{3} \cdot \mathrm{H}_{2} \mathrm{O}$ volume added of (a, b) $0.05 \mathrm{~mL},(\mathrm{c}, \mathrm{d}) 0.1 \mathrm{~mL},(\mathrm{e}$, f) $0.3 \mathrm{~mL}$, and $(\mathrm{g}, \mathrm{h}) 0.4 \mathrm{~mL}$. 

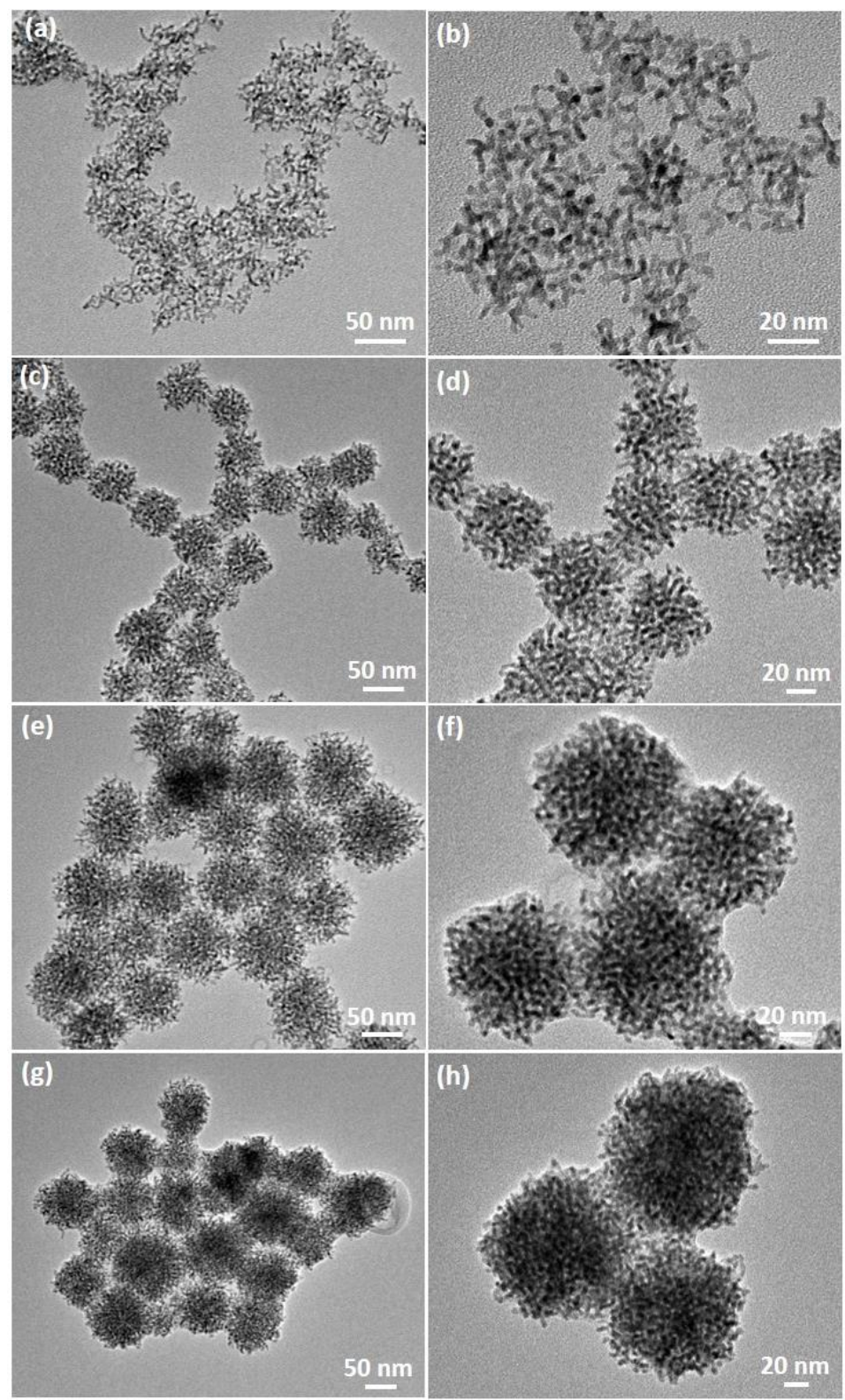

Figure S7. The effect of the DODAC concentrations in controlling the dendritic diameters of ternary PdBP alloy MSs. Typical TEM images of the PdBP MSs synthesized with initial DODAC concentration of (a, b) $0.3 \mathrm{mg} / \mathrm{mL}$, (c, d) $1 \mathrm{mg} / \mathrm{mL}$, (e, f) $9 \mathrm{mg} / \mathrm{ml}$, and (g, h) $24 \mathrm{mg} / \mathrm{mL}$. 


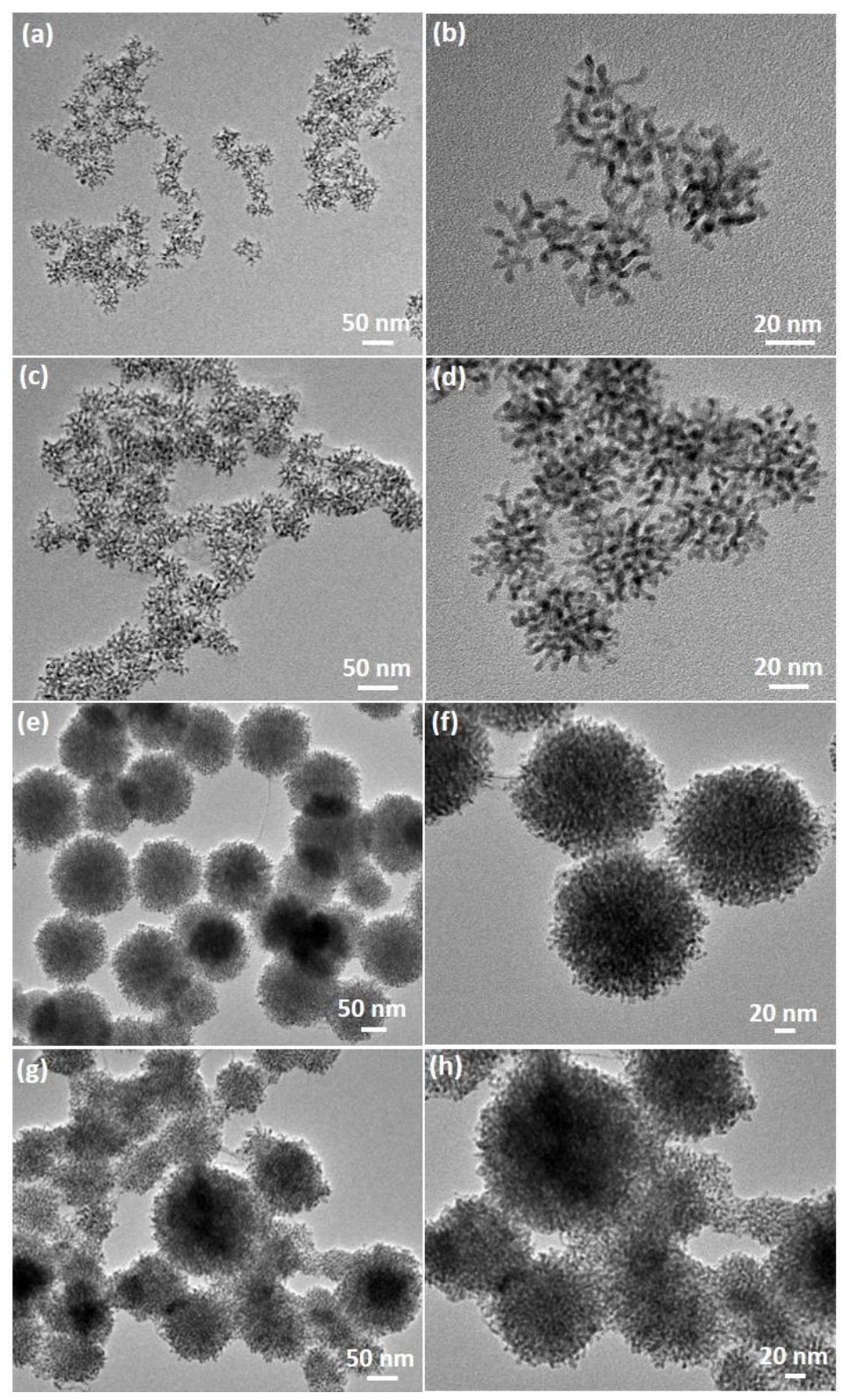

Figure S8. The effect of the Pd precursor concentrations in controlling the dendritic diameters of ternary PdBP alloy MSs. Typical TEM images of the PdBP MSs synthesized with initial $\mathrm{PdCl}_{4}{ }^{2-}$ volume $(10 \mathrm{mM})$ of $(\mathrm{a}, \mathrm{b}) 0.1$ $\mathrm{mL},(\mathrm{c}, \mathrm{d}) 0.2 \mathrm{~mL},(\mathrm{e}, \mathrm{f}) 0.8 \mathrm{~mL}$, and $(\mathrm{g}, \mathrm{h}) 1.6 \mathrm{~mL}$. 

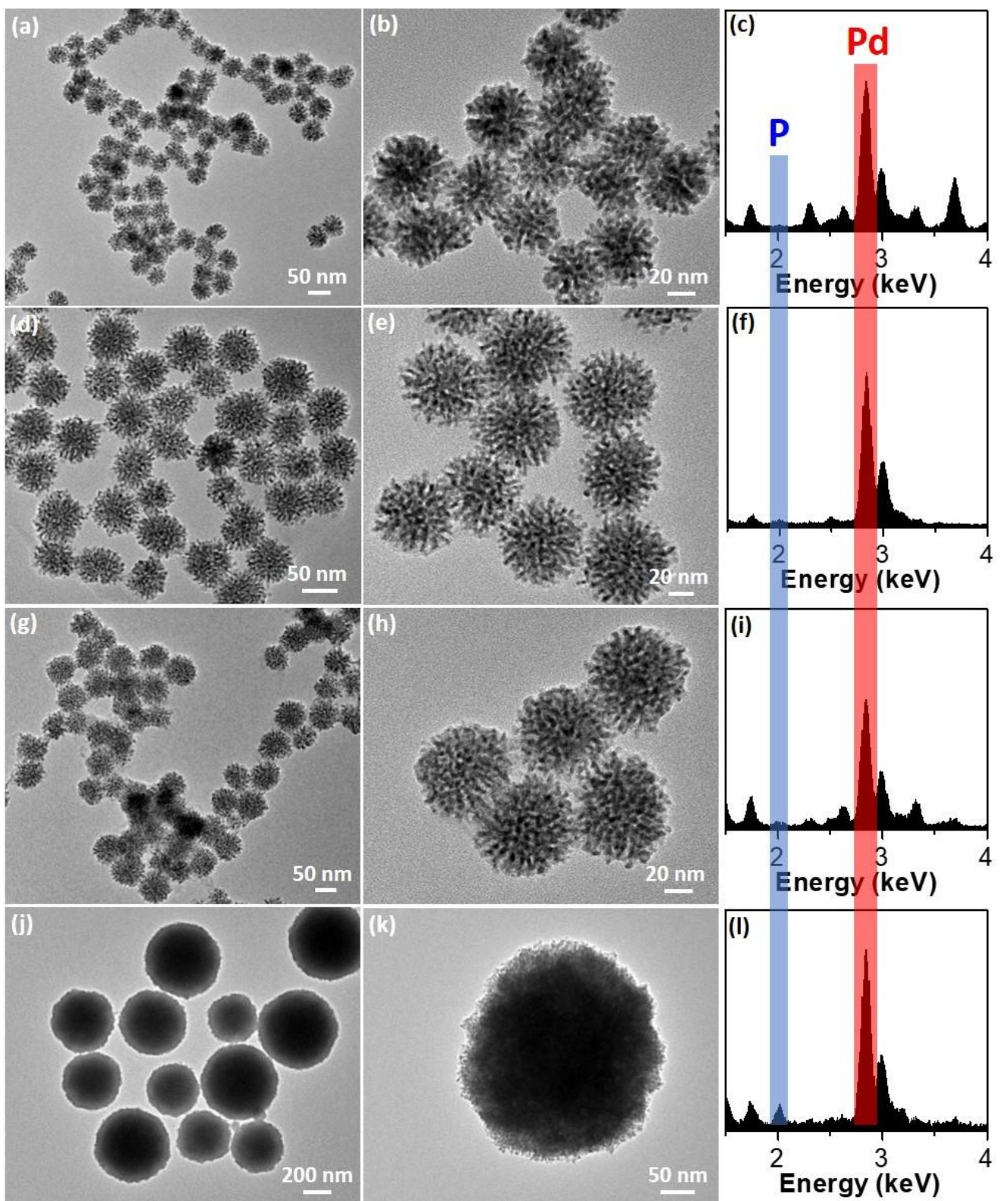

Figure S9. Synthesis of ternary PdBP MSs with different P contents. TEM images and EDS spectra of the PdBP MSs synthesized with initial $\mathrm{NaH}_{2} \mathrm{PO}_{2}$ amount of (a-c) 0 , (d-f) $0.3 \mathrm{mg}$, (g-i) $0.75 \mathrm{mg}$, and (j-1) $3 \mathrm{mg}$. The P content in ternary PdBP MSs is (a-c) 0, (d-f) 2.16 at. \%, (g-i) 4.31 at. \%, and (j-1) 11.4 at. \%, respectively. All compositional ratios were obtained by ICP-MS.

(Note: $B$ is undetectable in EDS spectra) 

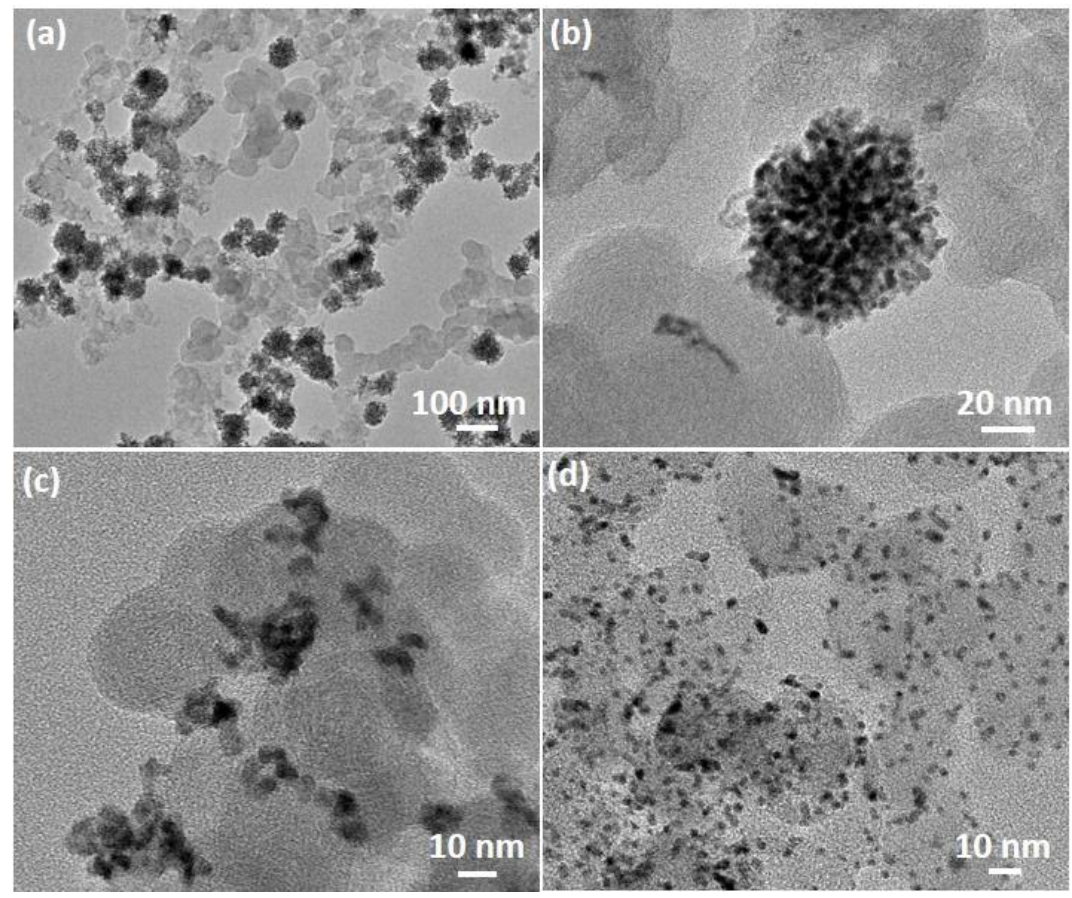

Figure S10. Structural characterizations of ternary PdBP alloy MSs and PdBP alloy NPs loaded on Vulcan XC-72 carbon, in addition to commercial Pt NPs on carbon.

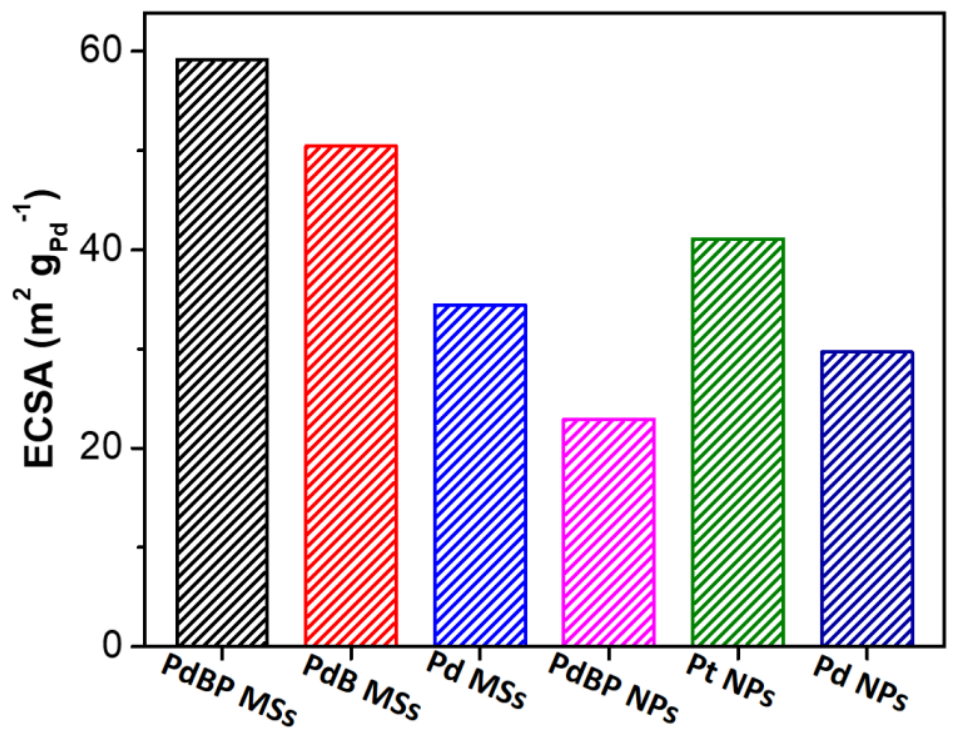

Figure S11. The calculated ECSAs of the PdBP MSs, PdB MSs, Pd MSs, PdBP NPs, commercial Pt and Pd NPs collected in $\mathrm{N}_{2}$-bubbled 0.1 M KOH. 


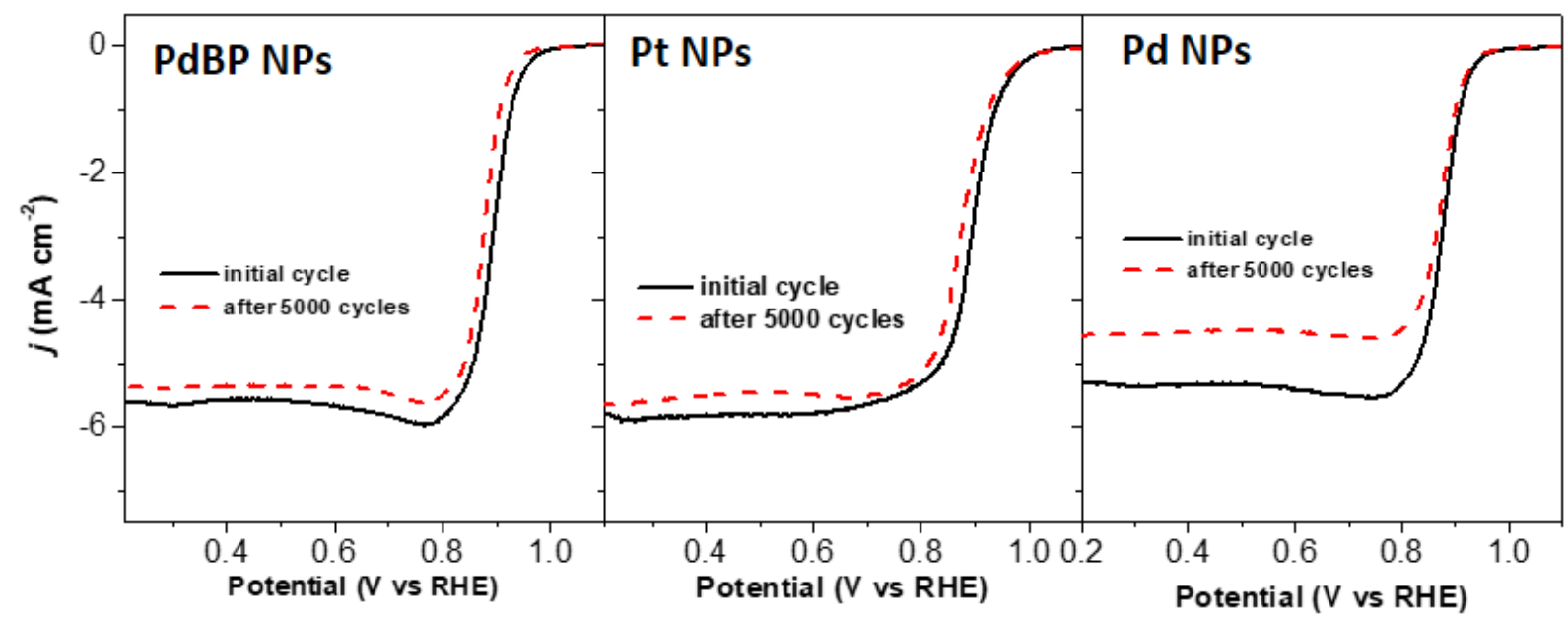

Figure S12. ORR polarization curves of the PdBP NPs, commercial Pt and Pd NPs in $\mathrm{O}_{2}$-saturated $0.1 \mathrm{M} \mathrm{KOH}$ before and after 5,000 cycles of potential sweeps.
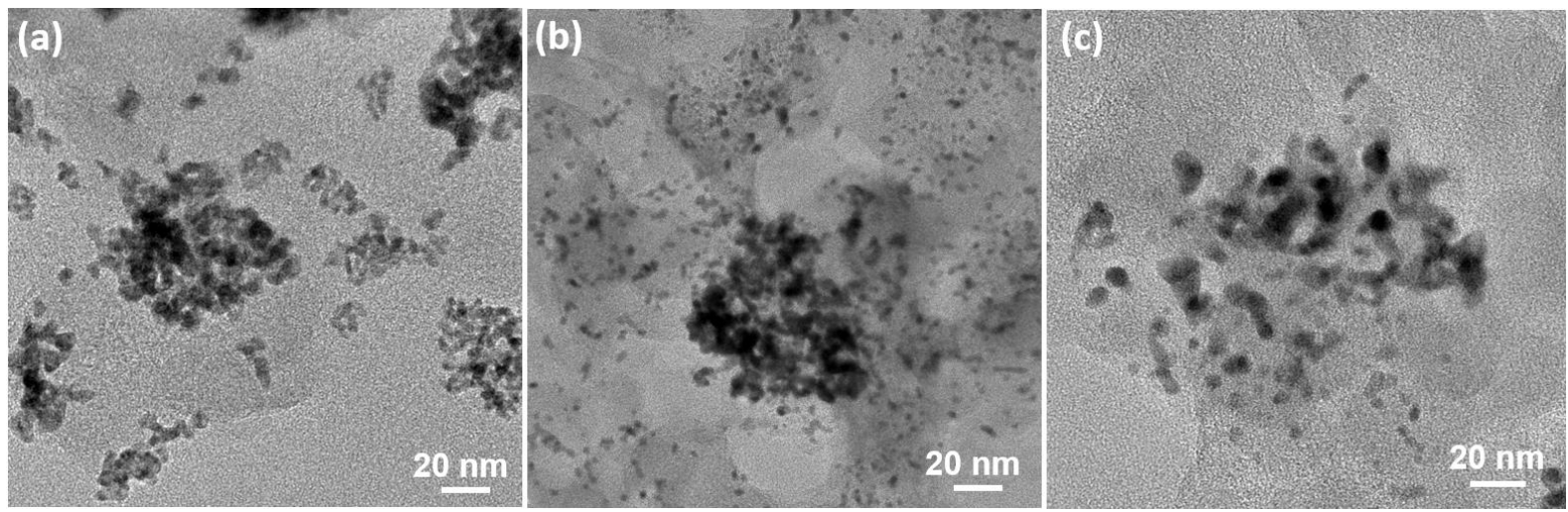

Figure S13. TEM images of (a) PdBP NPs, (b) commercial Pt NPs and (c) Pd NPs after 5,000 cycles of potential sweeps for electrochemical ORR. 


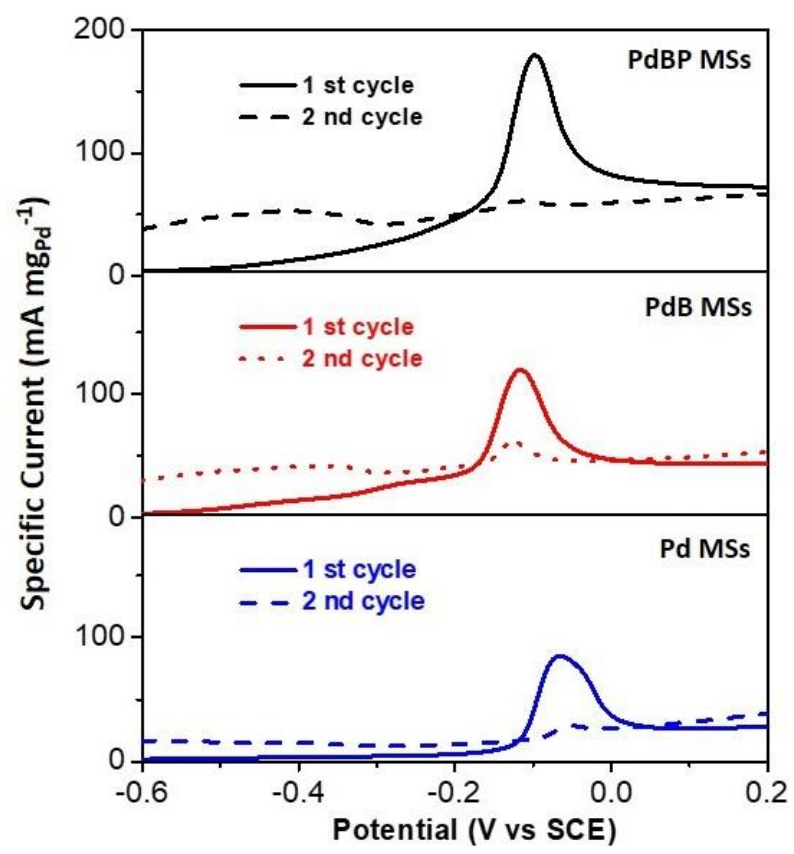

Figure S14. Electrocatalytic CO stripping curves of ternary PdBP alloy MSs, binary PdB alloy MSs, and monometallic Pd MSs.
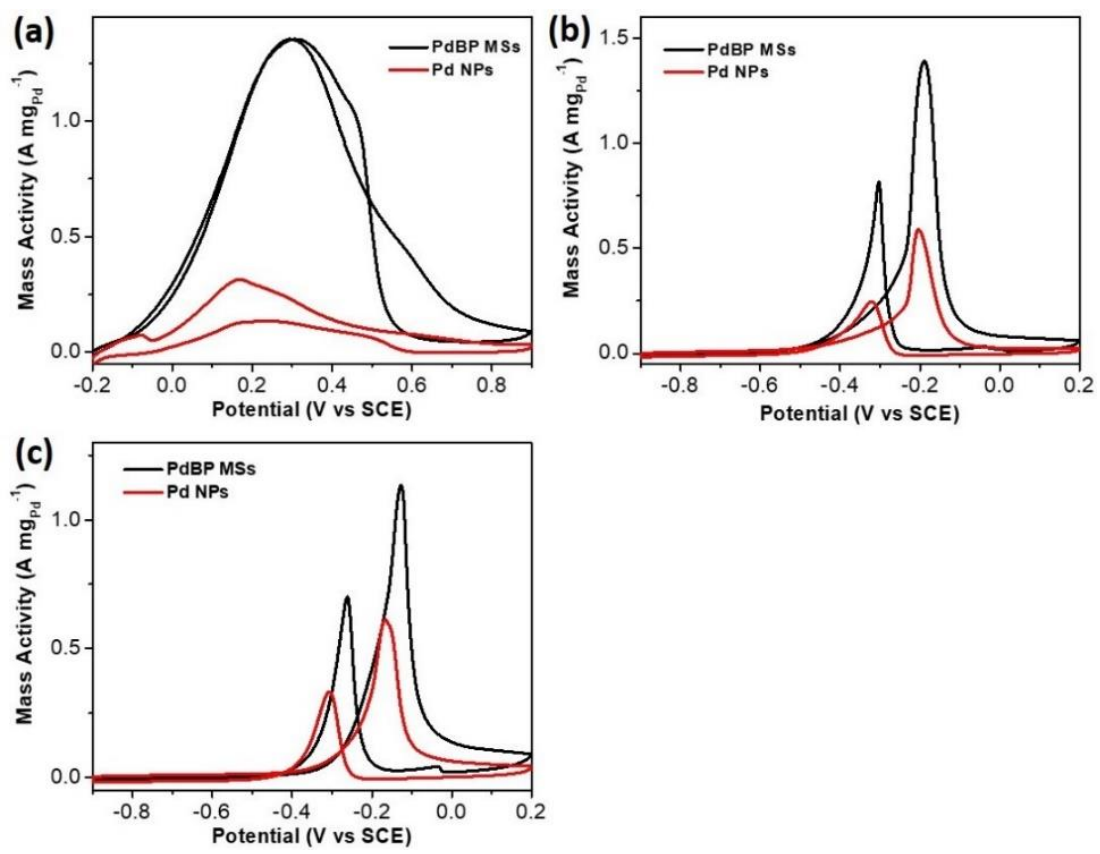

Figure S15. CV curves of ternary PdBP alloy MSs and commercial Pd NPs in (a) $0.5 \mathrm{M} \mathrm{H}_{2} \mathrm{SO}_{4}$ and $1.0 \mathrm{M}$ formic acid, (b) $1.0 \mathrm{KOH}$ and 1.0 M methanol, (c) $1.0 \mathrm{M} \mathrm{KOH}$ and $0.1 \mathrm{M}$ glycerol. 
Table S1. Summarization of electrochemical ORR performance of Pd-based nanoalloys in an alkaline media.

\begin{tabular}{|c|c|c|c|}
\hline No. & Catalysts & $\begin{array}{c}\text { Mass Activity (at } 0.9 \mathrm{~V}) \\
\left(\mathrm{A} \mathrm{mgPd}^{-1}\right)\end{array}$ & Refs \\
\hline 1 & $\begin{array}{c}\text { Dendritic PdBP alloy } \\
\text { MSs }\end{array}$ & 1.45 & This work \\
\hline 2 & $\mathrm{Pd}_{3} \mathrm{~Pb}$ nanosheets & 0.78 & $\begin{array}{c}\text { Small Method 2018, } 2, \\
1700331\end{array}$ \\
\hline 3 & $\mathrm{Pd} / \mathrm{WO}_{\mathrm{x}}$ hybrids & 0.216 & $\begin{array}{l}\text { J. Am. Chem. Soc. } \\
\mathbf{2 0 1 6}, 136,11687\end{array}$ \\
\hline 4 & Pd-B NPs & $\sim 1.14$ & $\begin{array}{c}\text { Angew. Chem. Int. Ed. } \\
\text { 2016, 55, 6842 }\end{array}$ \\
\hline 5 & $\mathrm{Pd}_{3} \mathrm{~Pb} \mathrm{NPs} / \mathrm{C}$ & 0.169 & $\begin{array}{c}\text { Nano Lett. 2016, 16, } \\
2560\end{array}$ \\
\hline 6 & $\mathrm{Pd}_{3} \mathrm{Fe} \mathrm{NPs} / \mathrm{C}$ & 0.43 & $\begin{array}{c}\text { J. Am. Chem. Soc. } \\
\mathbf{2 0 1 5}, 137,7278\end{array}$ \\
\hline 7 & $\mathrm{PdCuCo} \mathrm{NPs} / \mathrm{C}$ & 0.13 & $\begin{array}{l}\text { J. Am. Chem. Soc. } \\
\mathbf{2 0 1 4}, 136,15026\end{array}$ \\
\hline 8 & Pd-B NPs/C & 0.97 & $\begin{array}{c}\text { Chem. Mater. 2017, 29, } \\
10060\end{array}$ \\
\hline 9 & $\mathrm{Pd}_{3} \mathrm{~Pb}$ nanowires & 0.61 & $\begin{array}{c}\text { J. Mater. Chem. A } \\
\text { 2017, 5, } 23952\end{array}$ \\
\hline 10 & 50-nm PdCu Tetrapods & 0.29 & $\begin{array}{c}\text { ChemCatChem } \mathbf{2 0 1 8}, \\
10,925\end{array}$ \\
\hline
\end{tabular}

